\title{
Interna structure and nucleus formation in Sacculina polygenea (Crustacea: Cirripedia: Rhizocephala: Sacculinidae)
}

\section{Jørgen Lützen}

\begin{abstract}
The root system and nucleus formation in the colonial rhizocephalan Sacculina polygenea Lützen \& Takahashi has been reinvestigated and found to correspond to those of other related species. A conflicting opinion of these subjects recently proposed by Russian zoologists is due to the fact that these authors have mistaken a number of host structures for parts of the parasite's root system.
\end{abstract}

\section{Introduction}

Isaeva et al. (1999, 2001) and Shukalyuk \& Isaeva (2000) recently reported on the organization of the root system and the mode of asexual reproduction in the northwest Pacific sacculinid Sacculina polygenea Lützen \& Takahashi, a parasite of the littoral crab Hemigrapsus sanguineus (de Haan). Although they described the late development of the primordial externae correctly, their description of the early development differs significantly and fundamentally from results presented earlier by Takahashi \& Lützen (1998), and this has prompted the present reinvestigation of my earlier published material.

The general life cycle of rhizocephalans has been summarized by Høeg \& Lützen (1985, 1995, 1996). The complete life cycle is only known for a single species, the sacculinid Loxothylacus panopaei (Gissler) (see Glenner, 2001). Terms used in the following text are explained as follows. The externa is the reproductive body and in sacculinids it is borne ventrally on the abdomen of the host crab; it is solely concerned with sexual reproduction. The externa (or externae in asexually reproducing species) is/are connected to the parasite's trophic organ, the interna or root system, which is located within the host abdomen and cephalothorax. Primordial externae arise as so-called nuclei that are part of the root system and are located in the crab's abdomen, although they may start their development in the cephalothorax. A nucleus is located within a tumor, an expansion of the root system with an interior consisting of a loose tissue of widely separated, stellate cells.

\section{Materials and Methods}

As new material was not available, I reexamined part of my earlier section series of Hemigrapsus sanguineus parasitized by $S$. polygenea. The processing of this material was described by Takahashi \& Lützen (1998). It comprises $10 \mu \mathrm{m}$ thick continuous Paraplast ( $R$ ) serial sections of the abdomens and part of the cephalothorax of 10 sacculinized crabs and a few non-sacculinized crabs. Because of the considerable thickness of the sections, the images are not optimal. In addition, I studied a few slides of cross-sections of abdomens of $H$. sanguineus parasitized by $S$. polygenea that were kindly placed at my disposal by Dr. Valeria Isaeva, Institute of Marine Biology, Russian Academy of Sciences, Vladivostok, Russia. 


\section{Results}

Figure 1 presents a series of nuclei and tumors arranged to illustrate the growth of the early nucleus from a diameter of $c a$. $20 \mu \mathrm{m}$ to almost $50 \mu \mathrm{m}$ and the accompanying expansion and change in shape of the tumor. The illustrated stages are each chosen from among ca. 300 examined stages of the same size class (from ten sectioned crabs). In the present study, which aimed to document the development of the earliest nuclei, it was deemed unnecessary to present larger (and older) tumors/nuclei. Subsequent development takes exactly the same course as in other species of three genera of sacculinids (Delage, 1884: Sacculina; Smith, 1906: Drepanorchis; George, 1959: Heterosaccus).

The smallest recorded nuclei (15-25 $\mu \mathrm{m})$ and tumors always occurred at the tips of rootlets, which as a result had often swollen into small buds (Fig. 1-1,2,3). Accompanying bud-formation, the cuticularized epidermis surrounding these small tumors typically increased in height and stainability, a fact which considerably helps in the detection of these small stages. In favorable sections, the nucleus' small prospective mantle cavity was often seen to have fused with the inside of the bud's epidermis (Fig. 1-2).

In later stages the tumors expand proportionally much more than the nuclei. Nuclei of ca. $50 \mu \mathrm{m}$ in diameter often have tumors with dimensions of $250 \times 300 \mu \mathrm{m}$ (Fig. 1-8). In all growth stages, the nucleus is always positioned superficially within the tumor. Opposite the nucleus, larger tumors usually extend into many smaller or larger rootlets.

Even the smallest buds contained a minute vesicle associated with a small, compact body, which represent the earliest rudiments of the mantle cavity and visceral mass, respectively. In nuclei of $c a$. $50 \mu \mathrm{m}$ in diameter or larger, it was possible to recognize a cuticular lining in the mantle cavity and a rudimentary ovary centrally in the visceral mass (Fig. 1-8).

Figures 2-4 illustrate structures that are relevant for the Discussion. An expansion of the root system is always present beneath the stalk of the externa (Fig. 2). Within the cephalothorax of parasitized crabs numerous rootlets lie between the diverticula of the host's digestive gland (Fig. 3). Rootlets are particularly abundant in the first segments of the abdomen and may even invade a cluster of subgastrodermal glands, which occur in a zone circumscribing the boundary between the crab's midgut and hindgut (Fig. 4). The glands, which in the illustrated case are only superficially invaded by rootlets, consist of many small acini composed of relatively few large cells with darkly staining cytoplasm and peripherally placed nuclei.

\section{Discussion}

The material used by the Russian authors differs from my own only in that theirs was collected in Vostok Bay, Siberia, Sea of Japan, while my specimens are from the Amakusa Islands, Kyushu, Japan. In both cases the host crabs were $H$. sanguineus collected at the shore.

\section{The organization of the root system}

The general layout of the root system in sacculinids is very simple (Delage, 1884; Smith, 1906; Krüger, 1940; Hoshino, 1965). Beneath the point where the stalk of the externa penetrates the integument of the host, the root system has a sacshaped enlargement, from which a large number of rootlets issue. By branching profusely, the rootlets penetrate in between many organs of the host. An organ that is especially heavily infiltrated by the rootlets is the digestive gland (hepatopancreas), but the rootlets never enter the tubular diverticula of the gland. The epidermis of the rootlets consists of a simple, cuticle-producing epithelium, which is often associated with a subjacent layer of 

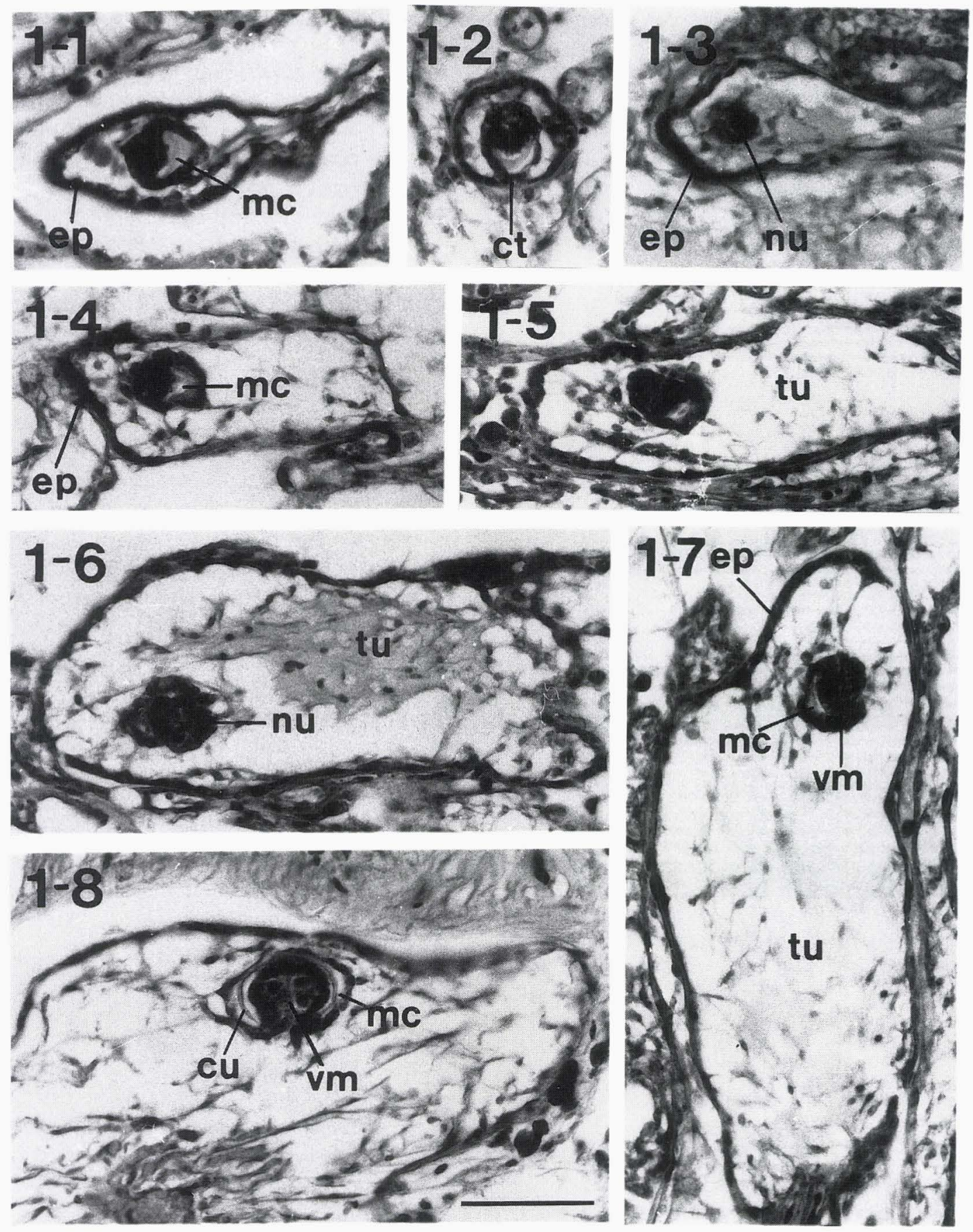

Fig. 1. Sacculina polygenea. Eight successive stages (1-8) in the development and expansion of nuclei and tumors. ct, contact between the epithelia of mantle cavity and bud; ep, frontal epithelium of bud, exhibiting increased height and stainability; mc, prospective mantle cavity lined by cuticle (cu); nu, nucleus; tu, tumor; vm, prospective visceral mass. $10 \mu \mathrm{m}$ thick paraplast sections stained with hematoxylin and eosin. Scale bar $50 \mu \mathrm{m}$. 


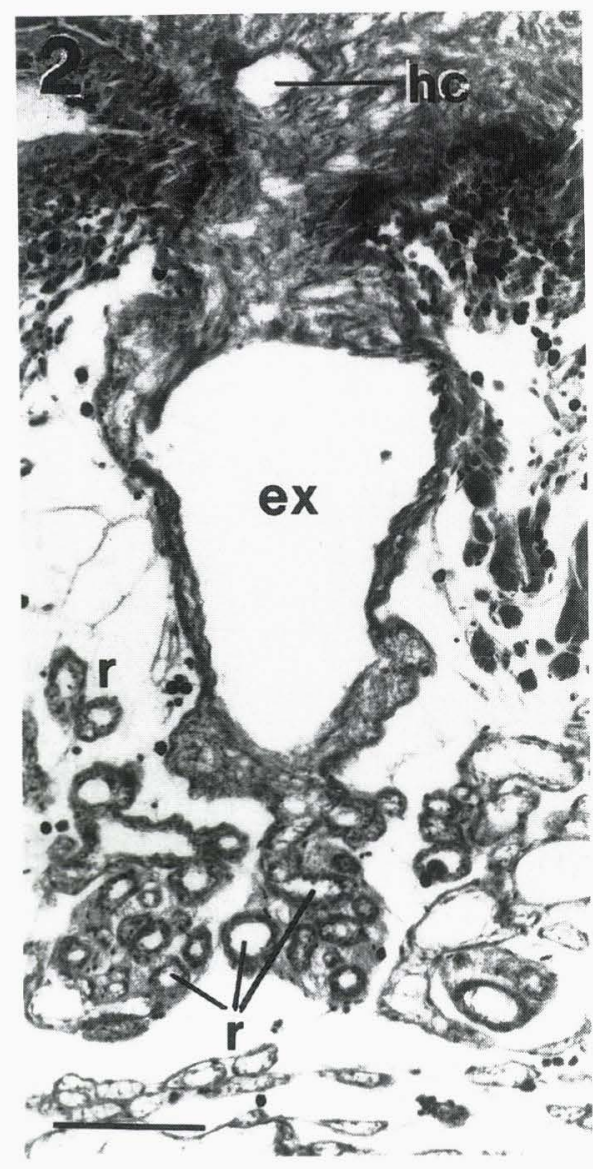

Fig. 2. Sacculina polygenea. Expansion of the root system (ex) underneath the stalk of the externa and ramification of rootlets ( $r$ ) from it; the expansion is continuous with the hemocoelic canal (hc) running through the stalk. $10 \mu \mathrm{m}$ thick paraplast section stained with hematoxylin and eosin. Scale bar $100 \mu \mathrm{m}$.

axial cells (Bresciani \& Høeg, 2001). The structure of the root system and the histology of the roots of Sacculina polygenea as reported by Takahashi \& Lützen (1998), and those of $S$. plana Boschma reported by Liu \& Lützen (2000), agree with this description (Fig. 2).

Shukalyuk \& Isaeva (2000) and Isaeva et al. (2001) arrived at quite another conclusion when investigating the morphology of the root system in S. polygenea. They reported it to be differentiated into two distinct systems: narrow distal rootlets and much larger transport trunks (or transport canals). They believed that the trunks connected the externae and/or their primordia with the rootlets. Although they did not present any histological sections of rootlets issuing from the trunks, they did provide cross-sections of the latter (Shukalyuk \& Isaeva, 2000, fig. 1d; Isaeva et al., 2001, fig. 2E). In these figures the diameter of the trunks ( $\mathrm{ca} .125-200$ $\mu \mathrm{m}$ ) is seen to exceed that of the rootlets by several times. However, it is evident that the authors mistook the tubular diverticula of the host's digestive gland with what they construed to be transport trunks. According to their description, the lining of the purported trunks is made up of a longitudinally folded epithelium, but this is exactly characteristic of the digestive gland diverticula. The diameter and average wall thickness of the diverticula in $H$. sanguineus (Fig. 3) also matches that of the "trunks". Furthermore, a careful examination by me of several sectioned externae in situ has shown that although the hemocoelic canal penetrating the stalk of the externa expands to a basin underneath the stalk basis, the rootlets issue directly from this expansion (Fig. 2), as has been reported also in other species. Even if it may give off a few larger roots as well, they are always short and their walls are much thinner than the "transport trunks", and smooth, never folded. A single diverticulum and many rootlets were illustrated side by side in crosssection by Hoshino (1962: fig. 2, pl. I, fig.1; Pachygrapsus crassipes Randall parasitized by $S$. confragosa Boschma) and by Takahashi \& Lützen (1998: fig.5; present species).

Figure 5 (center and right frame) in Isaeva et al. (2001) sums up their interpretation of the root system in S. polygenea. It falsely shows how the rootlets fuse with the "transport trunks", which is, of course, impossible. The error becomes all the more incomprehensible in light of the fact 
that the digestive gland diverticula in $H$. sanguineus never penetrate into the part of the abdomen where the externae are attached.

The origin of nuclei in asexually reproducing rhizocephalans

Until the study by Glenner (2001), the exact origin of the earliest nuclei present in the root system was not known. By a patient and meticulous examination of the fine structure of the cyprids and later invasive larval stages of the sacculinid Loxothylacus panopaei, Glenner succeeded to trace the origin of the earliest known nuclei of the root system-and at the same time the externae-back through the vermigon and the kentrogon to the female cyprid larva. While $L$. panopaei is predominantly solitary on its host, many rhizocephalans are constantly colonial. It is generally recognized that all externae in these species arise by asexual reproduction through a budding process from the interna, which itself has originated from a single female cyprid. The externae in some colonial species may number several hundreds or even thousands (Jespersen \& Lützen, 1992; Høeg \& Lützen, 1993); clearly, therefore, the explanation of how the nucleus/externa originates in a solitary rhizocephalan fails to explain how the many nuclei/externae arise in colonial forms. If one does not resort to the unlikely explanation that a single introduced nucleus splits or buds into many new ones, one is left with the alternative that the externae develop from nuclei that are formed de novo within the root system. At the moment, however, this question has not been settled.

Asexual reproduction occurs in several families of Rhizocephala that do not collectively form a natural taxon. The origin or the formation of the nuclei is not necessarily the same in all of them, but in a number of species the smallest nuclei have been discovered in slightly swollen rootlet terminations, which by expansion

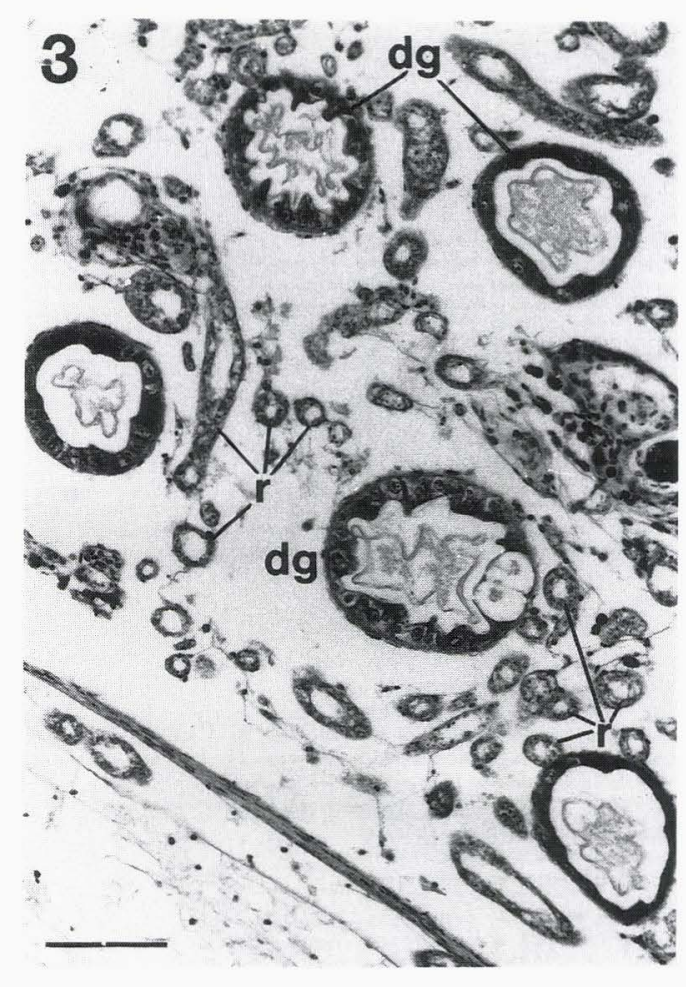

Fig. 3. Diverticula of the digestive gland $(\mathrm{dg})$ of the host $(H$. sanguineus) and rootlets $(\mathbf{r})$ of $S$. polygenea. $10 \mu \mathrm{m}$ thick paraplast section stained with hematoxylin and eosin. Scale bar $100 \mu \mathrm{m}$.

form a young tumor around the growing nucleus (Potts, 1915; Lützen, 1992; Lützen \& Jespersen 1992; Lützen \& Du, 1999). As documented in the present study, and as has also been shown and illustrated earlier for this species (Takahashi \& Lützen, 1998) and the allied S. plana (see Liu \& Lützen, 2000), the earliest nuclei are invariably localized within bud-like enlargements of the tips of the rootlets. The recorded minimum size of these small nuclei is $c a .15 \mu \mathrm{m}$ in both species. The smallness of the nuclei combined with the thickness of the sections $(10 \mu \mathrm{m})$ made it impossible to study the details of their structure; it was, however, repeatedly noted that the nuclei at one place adhered to the inside of the surrounding epidermis (Fig. 1-2). This may offer a clue as to how 


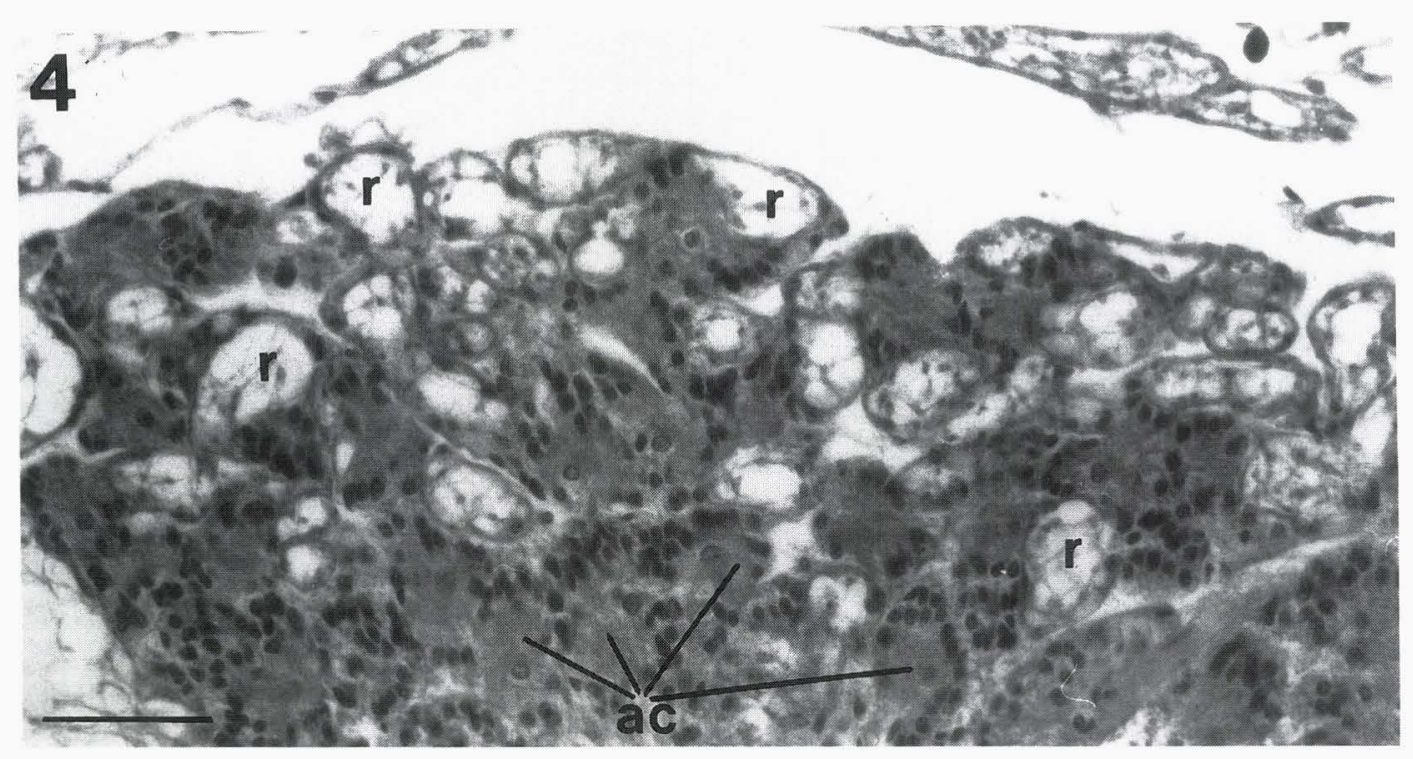

Fig. 4. Rhizocephalan rootlets ( $\mathrm{r}$ ) penetrating between the acini (ac) of the subgastrodermal glands of the host gut. $10 \mu \mathrm{m}$ thick paraplast section stained with hematoxylin and eosin. Scale bar $50 \mu \mathrm{m}$.

they arise. Rubiliani et al . (1982) showed that several nuclei are formed temporarily in the early interna of Sacculina carcini (Thompson), arising by a local invagination of the epidermis; the invagination dedifferentiates and subsequently produces the rudiments of the future mantle cavity and ovary. The association of the smallest nuclei with the epidermis in $S$. polygenea and $S$. plana might indicate that they also arise by invagination. Derivation of the cuticularized epidermis of the mantle cavity from the equally cuticle-lined root epidermis could be easily explained, whereas formation of an ovary from cells of ectodermal origin is unorthodox. If true, it has nevertheless a parallel in the morphogenesis as a result of bud formation exhibited by some colonial ascidians (family Botryllidae). In the buds of these ascidians the ectodermally derived atrial epithelial lining is totipotent and gives rise to nearly all tissues of the blastozooid, including such mesodermal structures as the pericardium, epicardium, and gonads (Berrill, 1941, 1947).
Isaeva et al. (1999, 2001) believe that the nuclei of $S$. polygenea develop from totipotent embryonic stem cells, which are said to accumulate to form numerous small nuclei consisting of compact clusters of non-differentiated cells. They report (p. 137) that these nuclei are located "inside the major portion of the interna ... close to the border between cephalothorax and abdomen." Their fig. 3A shows a number of these so-called nuclei, which, however, seem to be squeezed in between the elements of the root system rather than being part of it. I have studied these structures on slides borrowed from Dr. V. Isaeva, on which they are abundantly present. On comparing them with my own sections I became certain that 1) they are definitely not part of the root system, 2) they are constantly present in unparasitized as well as parasitized host crabs, and 3) they are identical with the acini of the subgastrodermal glands mentioned in the Results section. The similarity in structure and size of these so-called nuclei and the glandular acini is apparent 
if fig. 3B from Isaeva et al. (2001) is compared with Fig. 4 in the present paper.

Other bodies claimed to represent stages in the formation of primordia of externae are shown by Shukalyuk \& Isaeva (2000, fig. 1d: pe) and Isaeva et al. (2001, fig. 2E: PE). They resemble no other known stages in the development of any sacculinid and do not fit into the series of developmental stages illustrated in the present paper. They are obviously part of the host's digestive gland diverticula, and their unusual shape is possibly a result of poor histological preparation resulting in crumbling and partial detachment of the folded epithelial wall. Equally baffling is an epithelium-lined empty space claimed to be a later primordium (Isaeva et al., 2001, fig. 3 C, D) despite the absence in it of any landmarks such as a recognisable tumor or nucleus that could reveal its true nature. I am inclined to believe that the hollow structures shown in fig. $3 \mathrm{C}$ are parts of the coiled tubular hindgut caecum and that the structure labelled ICM (meaning internal cell mass) in fig. $3 \mathrm{D}$ is simply a tangentially sectioned wall of one of the tubes, which bends at this place.

The Russian authors have obviously mistaken a number of host structures for parts of the root system of $S$. polygenea and have therefore reached some odd conclusions, which are in conflict with all previous studies. The present paper certifies that the root system and nucleus formation in S. polygenea are the same as in other species of sacculinids.

\section{Literature Cited}

Berrill, N. J., 1941. The development of the bud in Botryllus. Biological Bulletin, 80: 169-184.

- , 1947. The developmental cycle of Botrylloides. Quarterly Journal of Microscopical Science, 88: 393-407.

Bresciani, J., \& Høeg, J. T., 2001. Comparative ultrastructure of the root system in rhizocephalan barnacles (Crustacea: Cirripedia: Rhizocephala). Journal of Morphology,
249: 9-42.

Delage, Y., 1884. Évolution de la sacculine (Sacculina carcini Thomps.) crustacé endoparasitaire de l'ordre nouveau des kentrogonides. Archives de Zoologie Expérimentale et Générale, ser. 2, 2: $417-$ 736.

George, A. I., 1959. Heterosaccus ruginosus (Boschma), a rhizocephalan parasite of the crab Neptunus sanguinolentus (Herbst). Journal of the Zoological Society of India, 11: 171-204.

Glenner, H., 2001. Cypris metamorphosis, injection and earliest internal development of the rhizocephalan Loxothylacus panopaei (Gissler). Crustacea: Cirripedia: Rhizocephala: Sacculinidae. Journal of Morphology, 249: 43-75.

Hoshino, K., 1962. Morphology of Sacculina confragosa Boschma, a rhizocephalan parasite of Pachygrapsus crassipes Randall, and changes of the host induced by parasitism. Contribution No. 5 from the Science Education Laboratory, Manazura Science Education Station, Faculty of Arts and Sciences, Yokohama National University, 12 pp. (In Japanese)

-1965 . On the root system of Sacculina confragosa Boschma, a rhizocephalan parasite attached to Pachygrapsus crassipes Randall. Researches on Crustacea, 2: 3-9.

Høeg, J. T., \& Lützen, J., 1985. Crustacea Rhizocephala. Marine Invertebrates of Scandinavia 6. 92 pp. Norwegian University Press, Oslo.

- \& - 1993. Comparative morphology and phylogeny of the family Thompsoniidae (Cirripedia, Rhizocephala, Akentrogonida), with descriptions of three new genera and seven new species. Zoologica Scripta, 22: 363-386.

, \& - 1995. Life cycle and reproduction in the Cirripedia Rhizocephala. Oceanography and Marine Biology, an Annual Review, 33: 427-485.

, \& — , 1996. Super-ordre des Rhizocéphales (Rhizocephala F. Müller, 1862). In: Forest J, (ed.), Traité de Zoologie, 7 (2) Crustacés Géneralités (suite) et Systématique (1re partie). pp. 541-568. Masson, Paris.

Isaeva, V. V., Rybakov, A.V., \& Kas'yanov, V.L., 1999. In vitro visualization of colonial organization in the interna of rhizocephalan barnacles Peltogasterella gracilis and Sacculina polygenea. Doklady RAN, 366: 840-842. (In Russian)

Isaeva, V. V., Shukalyuk, A.I., Trofimova, 
A.V., Korn, O.M., \& Rybakov, A.V., 2001. The structure of colonial interna in Sacculina polygenea (Crustacea: Cirripedia: Rhizocephala). Crustacean Research, 30: 133-146.

Jespersen, Å., \& Lützen, J., 1992. Thompsonia dofleini Häfele, a colonial akentrogonid rhizocephalan with dimorphic, ova- or sperm-producing, externae (Crustacea: Cirripedia). Zoomorphology, 112: 105-116.

Krüger, P., 1940. Cirripedia. In: H.G. Bronn, (ed.), Klassen und Ordnungen des Tiereichs, Bd. 5, Abt. 1, Buch 3, Teil 3: 1-560.

Liu, H.-C., \& Lützen, J., 2000. Asexual reproduction in Sacculina plana (Cirripedia: Rhizocephala), a parasite of six species of grapsid crabs from Taiwan. Zoologischer Anzeiger, 239: 277-287.

Lützen, J., 1992. Morphology of Thompsonia reinhardi, new species (Cirripedia: Rhizocephala), parasitic on the northeast Pacific hermit crab Discorsopagurus schmitti (Stevens). Journal of Crustacean Biology, 12: 83-93. , \& Du, P. T., 1999. Three colonial rhizocephalans from mantis shrimps and a crab in Vietnam, including Pottsia serenei, new species (Cirripedia: Rhizocephala: Thompsoniidae). Journal of Crustacean Biology, 19: 902-907.

, \& Jespersen, A., 1992. A study of the morphology and biology of Thompsonia littoralis (Crustacea: Cirripedia: Rhizocephala). Acta Zoologica, 73: 1-23.

Potts, F. A., 1915. On the rhizocephalan genus Thompsonia and its relation to the evolution of the group. Publications of the Carnegie Institution, 212: 1-32.

Rubiliani, C., Turquier, Y., \& Payen, G. G., 1982. Recherche sur l'ontogenèse des rhizocéphales. I. Les stades précoces de la phase endoparasitaire chez Sacculina carcini Thompson. Cahiers de Biologie Marine, 23: 287-297.

Shukalyuk, A. I., \& Isaeva, V. V., 2000. Intravital and histological studies of the internal organization of the rhizocephalan barnacle Sacculina polygenea. Russian Journal of Marine Biology, 26: 209-211.

Smith, G., 1906. Rhizocephala. Fauna und Flora des Golfes von Neapel, 29: 1-129.

Takahashi, T., \& Lützen, J., 1998. Asexual reproduction as part of the life cycle in Sacculina polygenea (Cirripedia: Rhizocephala: Sacculinidae). Journal of Crustacean Biology, 18: 321-331.

Address: Zoomorphology Department, Zoological Institute, Copenhagen University, Universitetsparken 15, DK-2100 Copenhagen $\varnothing$, Denmark E-mail: jlutzen@zi.ku.dk 